\title{
Living Tradition: A Study of Prehistoric Rock- paintings and Indigenous Art from District Sonbhadra, Southern Uttar Pradesh, India
}

\author{
By Indrani Chattopadhyaya*
}

In this I intend to weave together some emerging ideas on how to approach prehistoric art forms and art styles from an ethno-archaeological perspective by analyzing local tribal art traditions in the Kaimur region, in the district Sonbhadra, southern Uttar Pradesh (henceforth, U.P.), India. Prehistoric art is rooted in human evolution and has emerged gradually for finding solutions to many challenges of survival by people since 10,000 years ago. After studying more than twelve painted rock shelters of Prehistoric period, I have explored the art traditions and material culture of living tribal populations of Kol and Bhil in this area. This paper attempts to find out (i) how far back we could trace cultural roots and (ii) whether there is continuity in the cultural tradition (Paramparā) between the past and the present.

\section{Introduction}

In archaeological records, rock paintings are the most easily accessible cultural data. These paintings capture our imagination, conveying meaning like a "visual dialogue" between the world view of the artist from the past and the viewers in the present. Through these paintings, we can look at the workings of human mind and artist's comprehension of the world around him, and yet, we are far removed from that world in time. Alpert ${ }^{1}$ has established that there are cognitive continuities between Paleolithic cave painters and the ability of modern man to relate to these visual images, regardless of time. The rock paintings are depictions of moments or events at a particular time and there cannot be an absolute identification or understanding of its meaning, as in the case of an archaeological artefact - a stone tool or a decorated pot. The meaning in this case, is elusive because the artist has not only created his paintings with his own world views, cultural values and social concerns, but has also projected his sense of aesthetics and artistic perspective to enrapt his viewers. The Indian concept of aesthetic appreciation is a distinct kind of enjoyment and a critical judgment by sympathetic experts (sahrdaya pariksaka). This is a judgment that assesses the adequacy (samarthya) and appropriateness (aucitya) of the image. The proof of the

\footnotetext{
* Reader, Department of Anthropology, University of Delhi, India.

1. Barbara Olins Alpert, The Creative Ice Age Brain: Cave Art in the Light of Neuroscience (New York: Foundation 20 21, 2008), 186-190.
} 
aesthetics is in the experience and communicative skill of the artist to make his paintings transcend cultural and trans-cultural contexts beyond time and space.

Like the archaeological evidence, in early rock paintings, we are looking at the "fragmented past" and we seek patterns to get at the meaning of these paintings. Understanding the meaning of these paintings is like interpreting the meaningful action. Hermeneutics, the science of interpretation, especially Paul Ricoeur's theory of interpretation that considers meaningful action as a "Text,"2 helps us in understanding the abstract symbolic meanings of the rock paintings as we try to encode them from a participant-observer point of view, first to understand the rules and the codes of the cultures these rock paintings belong to - physical, biological, economic domains - and then critically examining them from the perspective that these art works were created more than 8,000 years ago. Artists put their own experience in their creation, so when we visit these painted sites we are visiting both the past and the present. Archaeologists reconstruct the past from their position in the present by recognizing the past patterns and by matching it with the present patterns, observable in the society. Anthropologists look at tribal/folk art as ethnographic category and study the uses of art to understand their relation with other aspects of culture in living peoples. Similarly, archaeologists study prehistoric art to study "idea culture" of humans from the past to reconstruct them as thinking, believing, feeling, creative peoples. Ethnoarchaeology provides links between the present and the past. Whereas archaeologists look at the long-term changes, ethnoarchaeologists study the short - term changes in the society to find out analogical answers for the behaviour of past societies. Ethnoarchaeology, an established sub-discipline of archaeology, systematically defines relationships between behaviour and material culture to ascertain how certain features of observable behavior are reflected in the archaeological finds.

After extensive ethnoarchaeological research in Africa, Ian Hodder ${ }^{3}$ has reached the conclusion that "material culture is meaningfully constituted ... . All human action is meaningful not simply because it communicates messages to other people ... material culture is constituted within frameworks of conceptual meaning." There is a dynamic relationship between the artefact and the context that gives it meaning. Hodder ${ }^{4}$ elaborates this point, thus: "By placing an object in a context, the context is itself changed. There is thus a dialectical relationship between object and context, between text and context. The context both gives meaning to and gains meaning from an object." Hermeneutics involves a process of anticipating what is being said or communicated and then checking it out. It is

2. Paul Ricoeur, Hermeneutics and Human Sciences, ed. and trans. John B. Thompson (Cambridge: Cambridge University Press, 1981).

3. Ian Hodder, Theory and Practice in Archaeology (London and New York: Routldge, 1992), 11.

4. Ibid., 13. 
not a straightforward matter to correlate archaeological finds with past social processes. In this paper an effort has been made to see the connection between archaeological finds and early rock paintings and to study the painting tradition of tribal peoples to see if there is any link between the present and the past, keeping in mind that societies are continuously being transformed.

\section{Palaeoenvironmental Setting}

The area of this study is Sonbhadra district in north-central India (Kaimur hills and plateau), north of river Son and south of river Belan, lying in the southeastern corner of U.P. ${ }^{5}$ (Figure 1).

It is covered in the Survey of India topographical sheet no $63 \mathrm{P}, \mathrm{L}$ and $64 \mathrm{I}$ and $\mathrm{M}$, on a scale of 1:2,50,000. Sonbhadra, previously part of Mirzapur districst of U.P. was created as a separate district in 1991. It is bounded by Mirzapur and Chandauli districts of U.P., in the north, State of Jharkhand in the east, State of Madhya Pradesh in the west and State of Chhattisgarh in the south. The Kaimur plateau and hills consisting primarily of sandstone, limestone and shale have elevation approximately from $250 \mathrm{~m}$ to $400 \mathrm{~m}$ in height above mean sea level.

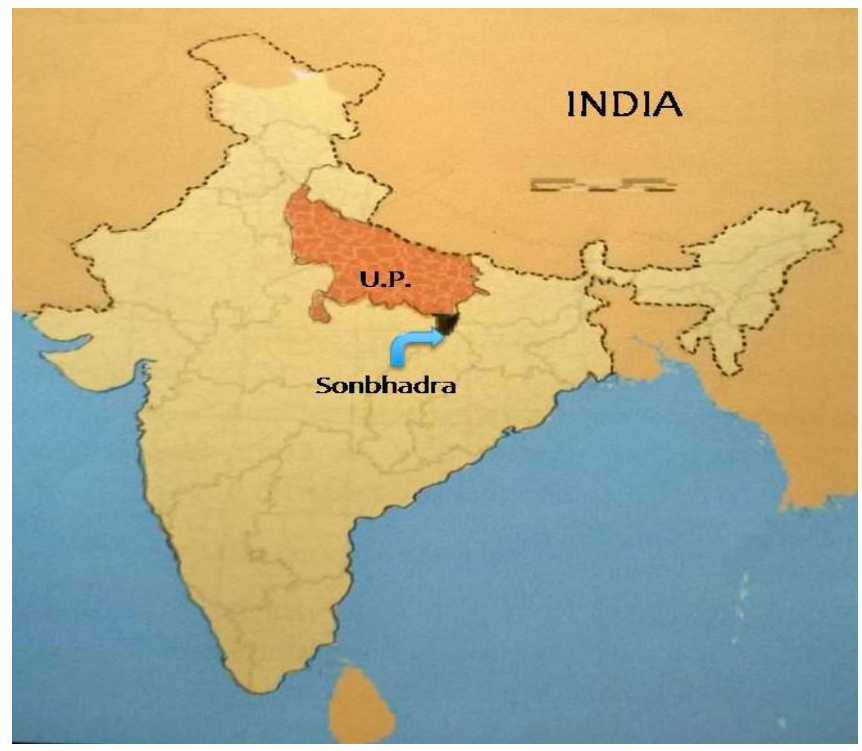

Figure 1. Map of India showing Sonbhadra (U.P.)

Archaeological and geological researches carried out in the middle Son valley since 1980 resulted in a rich collection of prehistoric stone tools, fossilized faunal remains and volcanic ash deposits from Toba mega-eruption in northern

5. Latitude $23^{\circ} 51^{\prime} 54^{\prime \prime} \mathrm{N}-24^{\circ} 46^{\prime} 18^{\prime \prime} \mathrm{N}$; Longitude $82^{\circ} 40^{\prime} 24^{\prime \prime} \mathrm{E}-83^{\circ} 33^{\prime} 15^{\prime \prime} \mathrm{E}$. 
Sumatra, dated $\sim 73,000$ years. ${ }^{6,7,89}$ A multidisciplinary team comprising archaeologists, geologists, geomorphologists, archaeo-zoologists, palaeobotanists have studied a nearby region, west of the area under consideration, to reconstruct the palaeo-environmental conditions in the Middle Son Valley. On the basis of the analyses of sediments from Son river formations, Williams and Royce $^{10}$ suggest palaeo-climatic shift from a dry, cold phase during the terminal Pleistocene to a wet, warm phase in early Holocene times. The latter condition further changed to comparatively dry, warm phase around Late Holocene. This resulted in changes in animal taxonomical composition that is reflected in rock paintings of the region covering a period from early to Late Holocene.

A complete sequence of prehistoric cultures in geo-stratigraphic context and their transformational stages have been studied in this area (Figure 2). The area has a long, probably the longest, prehistoric cultural sequence in India. The available archaeological evidence ${ }^{11,12}$ suggests a high degree of human adaptation and behavioral change. The lithic assemblage in this area points towards technological change, as well as changes in subsistence strategy, group mobility and behavioral adaptation. Painted rock shelters were first discovered in the plateau of Kaimur hills, then under Mirzapur District, by A.C.L. Carllyle in 1867-68. ${ }^{13}$ His report on these findings in the Proceedings of the Asiatic Society of Bengal in 1883 was published as notes. Later it was published by Vincent Smith. ${ }^{14}$ Since then there are more than 500 painted rock shelters found in Mirzapur and Sonbhadra districts in Kaimur (Figure 3). In this paper it is not possible to acknowledge each and every archaeologist who have worked really hard to

6. Govardhan Rai Sharma and Desmond Clark, "Palaeo-environments and prehistory in the Middle Son Valley, northern Madhya Pradesh," Man and Environment 6 (1982).

7. Govardhan Rai Sharma and Desmond Clark, Palaeoenvironments and Prehistory in the Middle Son Valley (Allahabad: Abinash Prakashan, 1983).

8. Robert. J. Blumenschine and Umesh Chandra Chattopadhyaya, "A preliminary report on the terminal Pleistocene fauna of the Middle Son valley," in Palaeoenvironments and Prehistory in the Middle Son Valley, ed. Govardhan Rai Sharma and Desmond Clark (Allahabad: Abinash Prakashan, 1983), 281-284.

9. Martin A.J. Williams et al., "Environmental impact of the 73 ka Toba supereruption in S. Asia," Palaeogeography, Palaeoeclimatology, Palaeoecology 284, no. 3-4 (2009).

10. Martin A. J. Williams and Keith Royce, "Alluvial history of the middle Son valley, north-central India," in Palaeoenvironments and Prehistory in the Middle Son Valley, ed. Govardhan Rai Sharma and Desmond Clark (Abinash Prakashan: Allahabad, 1983), 12-13.

11. Sharma and Clark, "Palaeo-environments and prehistory."

12. Sharma and Clark, Palaeoenvironments and Prehistory.

13. Archibald Campbell Carllyle, "Notes on lately discovered Sepulchral Mounds, Cairns, Caves, Cave Paintings and Stone Implements," Proceedings of the Asiatic Society of Bengal (1883).

14. Vincent A. Smith, "Pigmy flints," Indian Antiquary 35 (1906). 
bring these painted shelters to light. A project for identification and documentation of the sites with rock paintings are going on in the this region. The writer of this paper has documented and studied more than a dozen painted rock shelters in the Sonbhadra district over the last eight years.

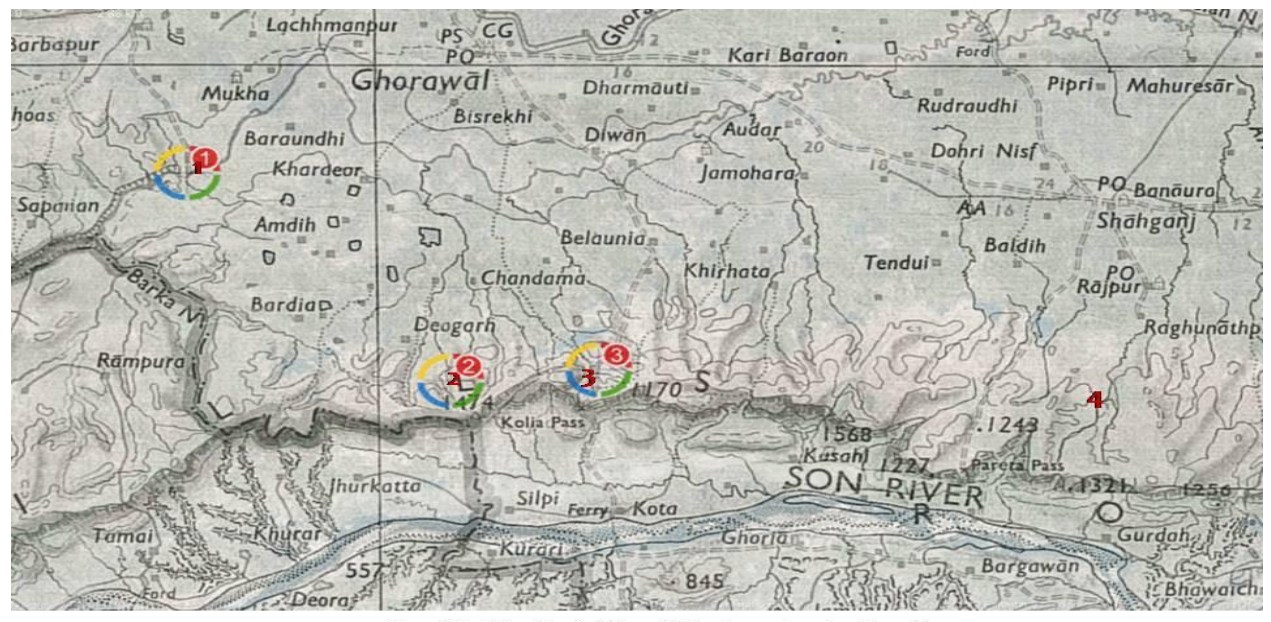

$$
\begin{aligned}
& \text { 1- Mukhadari (4 painted rock shelters) } \\
& \text { 2- Devgarh (1 painted rockshelter) } \\
& \text { 3- Kolia Ghat Pass (4 painted rock shelters) } \\
& \text { 4- Rajpur (1 painted rockshelter) }
\end{aligned}
$$

Figure 2. Research Area

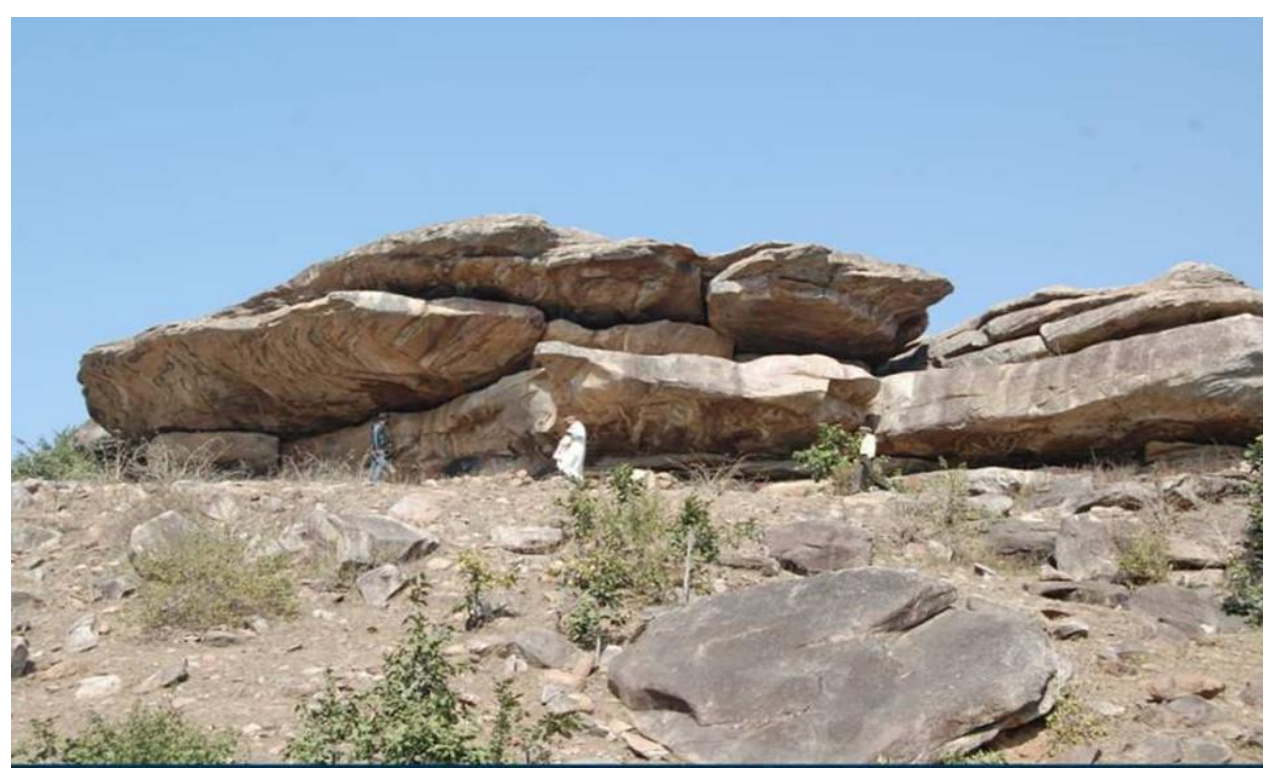

Figure 3. General View of the Rock Shelter 


\section{Painted Rock Shelters}

Prehistoric paintings from ten rock shelters from Sonbhadra (U.P.) are being discussed in this article (Table 1). The geological formations of the area consists of sandstone, limestone and shale that are susceptible to weathering and breakages thus, thousands of natural shelters were formed in this area.

\begin{tabular}{|l|l|}
\hline Lekhania (Rajpur) - One & $24^{\circ} 39^{\prime} 17.901^{\prime \prime} \mathrm{N}, 82^{\circ} 57^{\prime} 04.930^{\prime \prime} \mathrm{E}$ \\
\hline Mukkhadari - Four & $24^{\circ} 42^{\prime} 58.554^{\prime \prime} \mathrm{N}, 82^{\circ} 41^{\prime} 35.333^{\prime \prime} \mathrm{E}$ \\
\hline Kolia Ghat - Four & $24^{\circ} 38^{\prime} 50.802^{\prime \prime} \mathrm{N}, 82^{\circ} 48^{\prime} 14.4^{\prime \prime} \mathrm{E}$ \\
\hline Deogarh - One & $24^{\circ} 38^{\prime} 46.219^{\prime \prime} \mathrm{N}, 82^{\circ} 45^{\prime} 39.479^{\prime \prime} \mathrm{E}$ \\
\hline
\end{tabular}

Table 1. Location of Rock Shelters

Most of the shelters are shallow (Figure 4) about six to eight feet deep or formed by two or more rocks resting against each other. Not all the shelters have paintings, but some of these are crowded with paintings of animals. As well as anthropomorphic figures and mysterious signs and symbols. Prehistoric art, undoubtedly like other art forms, is multi-dimensional and has multi-layered meanings. Works of art have representational, expressive, and formal dimensions (Figure 5) and the artist, though affected by socio-cultural context, often rises above time and place. The spontaneous act of creation of art elevates the artist to a different plain and his work becomes multi-dimensional; something that goes beyond the spatio-temporal context.

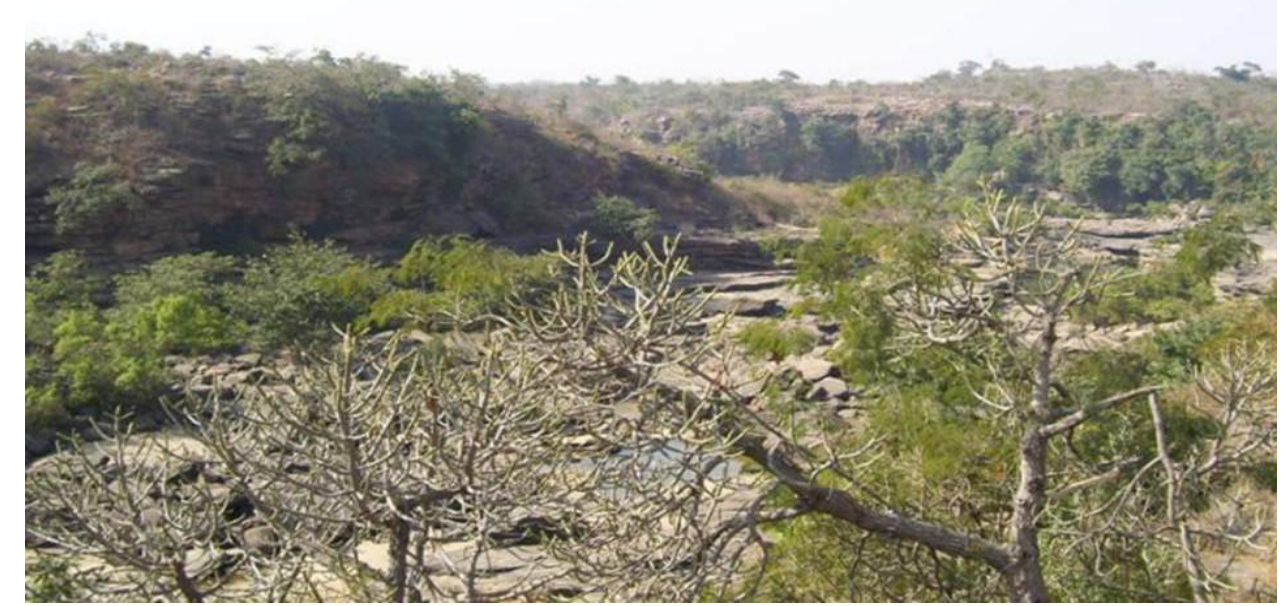

Figure 4. General View of the Area 


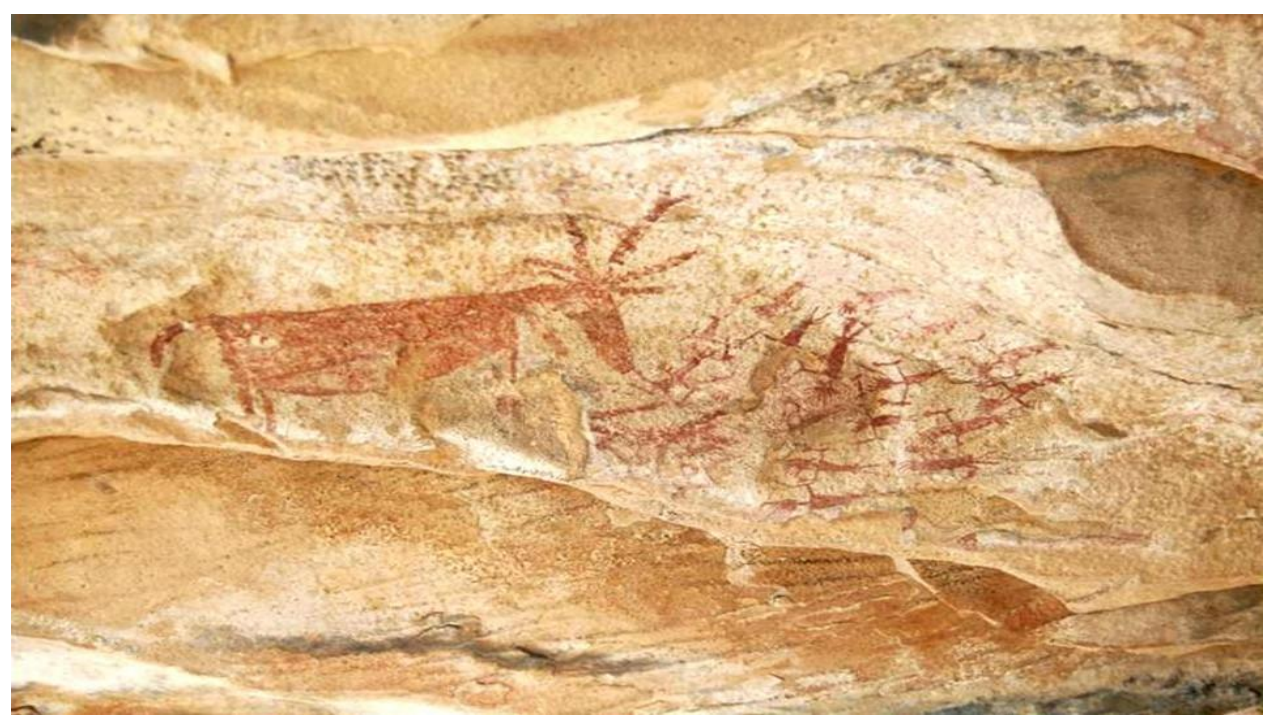

Figure 5. Paintings in Rock Shelter

Some of the basic aspects of prehistoric rock art studied so far by the scholars are: rock art as "ritual and magic,"15,16,17 as "symbolic and metaphoric practice,"18 as "territorial marker,"19 with an "ecological approach,"20,21,22 and as "an external memory store." 23

15. Margaret Conkey, "Boundedness in art and society," in Symbolic and Structural Archaeology, ed. Ian Hodder (Cambridge: Cambridge University Press, 1982).

16. Margaret Conkey, "Structural and semiotic approaches," in The Handbook of Rock Art Research, ed. David Whitley (California: Altamira Press, 2000).

17. Margaret Conkey, "Hunting for images, gathering up meanings," in HunterGatherers. An interdisciplinary perspective, ed. Catherine Panter-Brick, Robert Hugh Layton, Peter.Rowley-Conwy (Cambridge: Cambridge University Press, 2001).

18. Jean Clottes and David Lewis-Williams, "The mind in the cave- the cave in the mind: altered consciousness in the Upper Palaeolithic," Anthropology of Consciousness 9 (1998).

19. Richard Bradley, "Symbols and signposts - understanding the prehistoric petroglyphs of the British Isles," in The Ancient Mind: Elements of a Cognitive Archaeology, ed. Colin Renfrew, and Ezra Zubrow (Cambridge: Cambridge University Press, 1994).

20. Michael A. Jochim, "Palaeolithic art in ecological perspective," in Huntergatherer ecology in prehistory: A European perspective, ed. Geoff N. Bailey (Cambridge: Cambridge University Press, 1983).

21. Steven Mithen, "Ecological Interpretations of palaeolithic art," in Contemporary Archaeology in Theory: A Reader, ed. Robert B. Preucel and Ian Hodder (Oxford: Blackwell, 1996).

22. Paul Mellers, "Cognition and climate: why is Upper Palaeolithic cave art almost confined to the Franco-Cantabrian region?," in Becoming Human: Innovation in Prehistoric Material and Spiritual Culture, ed. Colin Renfrew and Iain Morley (Cambridge: Cambridge University Press, 2009).

23. Colin Renfrew, The Sapient Mind: Archaeology Meets Neuroscience (USA: Oxford University Press, 2009). 
The images of animals, cervid, bovid, equuas and elephus are painted in shelters where artists, who portrayed these images, would have come into regular contact with the animals. On the cave walls animal motifs predominate and are painted repeatedly (Table 2).

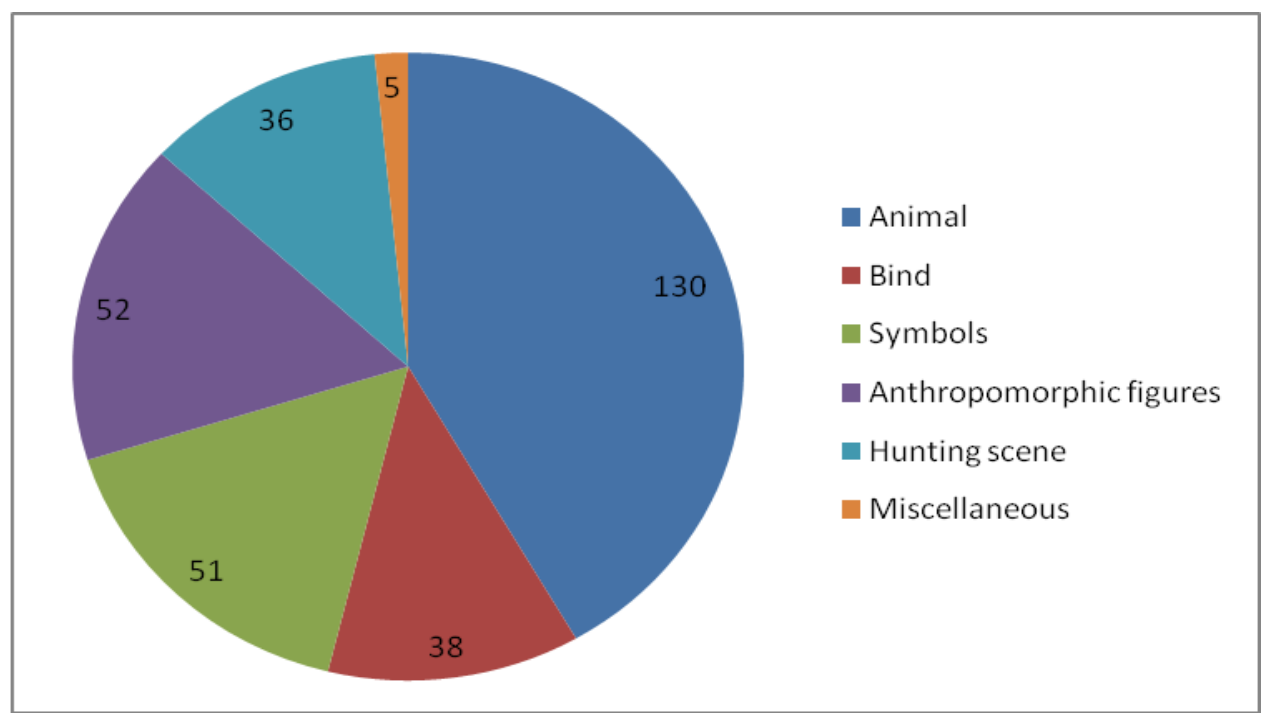

Table 2. Percentage of Different Motifs in Rock Paintings

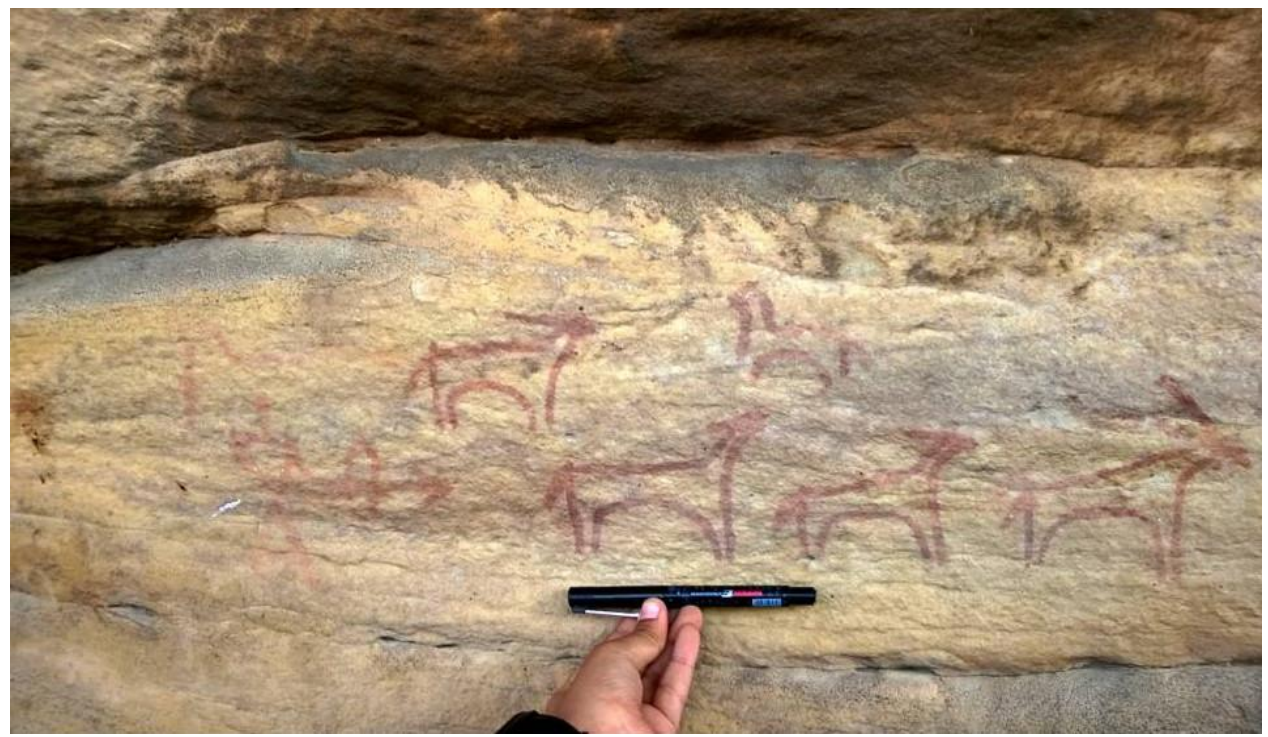

Figure 6. Paintings of Animals

The animal figures are drawn carefully with the least possible effort so that they are easily recognizable (Figure 6). But in some of the paintings Prehistoric artists' perception of the outline and shape of the animals were so perfect that the paintings are shown in 3D contours and the blank spaces depicted between contours are drawn perfectly. The artists have also taken full advantage of the undulated rock surfaces to draw the animal figure in three dimensions. 


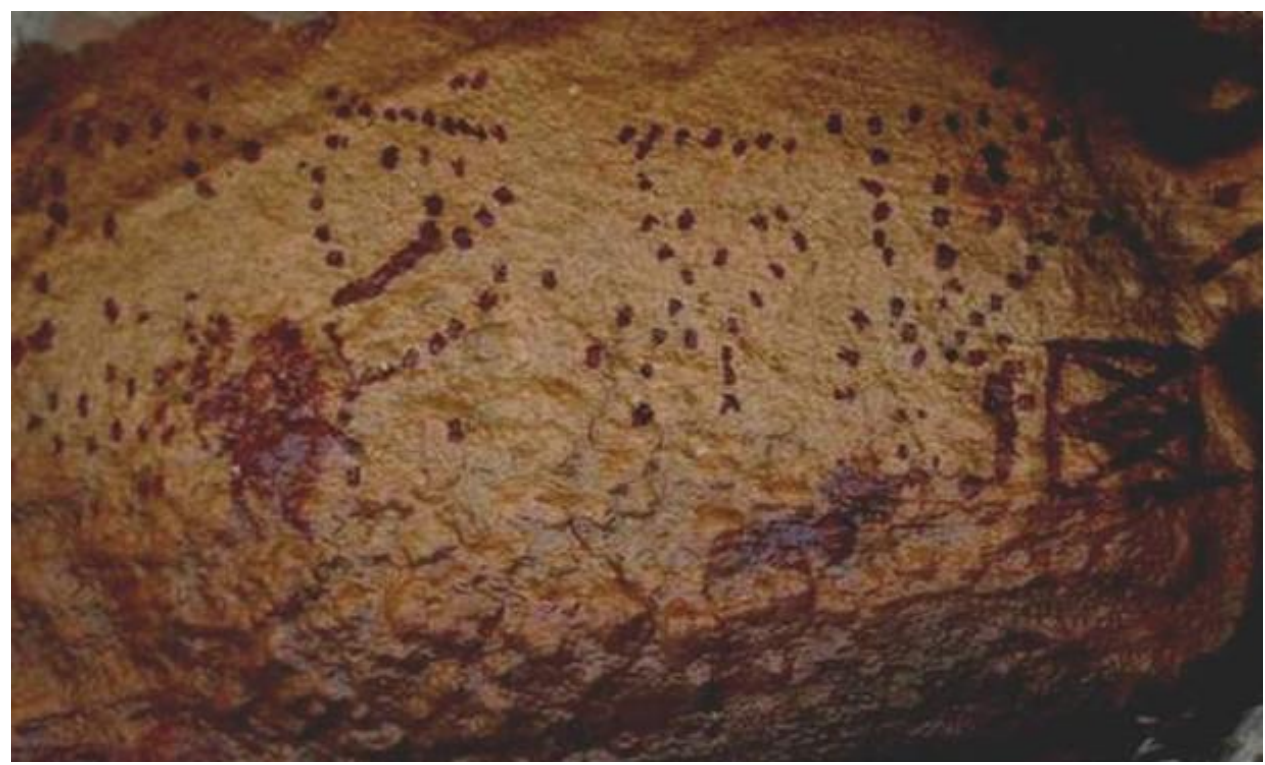

Figure 7. Geometric Symbol

There are also some painted geometric signs of triangles, rectangles, circles and composition made with dots (Figure 7) painted high up in the rock shelters. The identification of these geometric shapes and symbols has been considered in the context of Tantra symbols from Tantric philosophy in India. These symbols in religious practices of later period have significance at the narrative and structural levels. Like other ancient cultures these painted motifs suggest ability of the artist to visualize and reproduce abstract symbols. To quote Niharranjan Ray, ${ }^{24}$ "Indian art of any given time and space need not ... be approached and attempted to be understood in terms of a mystical or esoteric or exclusively transcendental meaning or significance. It is, by and large, frankly naturalistic, which according to the interpretation of Aitareya Brahmana (a Vedic text), means "in tune or harmony with nature" and is based on observation and in-taking of life, on perceptual understanding of man and nature."25

\section{Ethnographic Profile}

The villages near the painted rock shelters are mostly inhabited by Kol and Bhil/Bheel people of two heterogeneous tribal groups in India. The umbrella term for such indigenous minority aboriginal populations is Adivasi. Kol are the Mundari or Austro-Asiatic language speakers like the Bhumij, Ho, Kharia, Khairwar, Korwa, Munda, Oraon and Santhal tribes - all known as Kol. This distinctive family of languages resembles the language spoken by the aborigines of Australia. The Kol are mostly

24. Niharranjan Ray, An Approach to Indian Art (Chandigarh: Punjab University, 1974), 31-32.

25. Ibid. 
landless people in the area of study. Their traditional occupation was hunting and gathering and today they collect wood, leaves, fruits and honey from the forest to sell in the local village market (haat) (Figure 8), while some are engaged in tending animals in exchange of money. The $\mathrm{Kol}$ in this area are divided into two different endogamous groups - Rawtele and Rajuria.

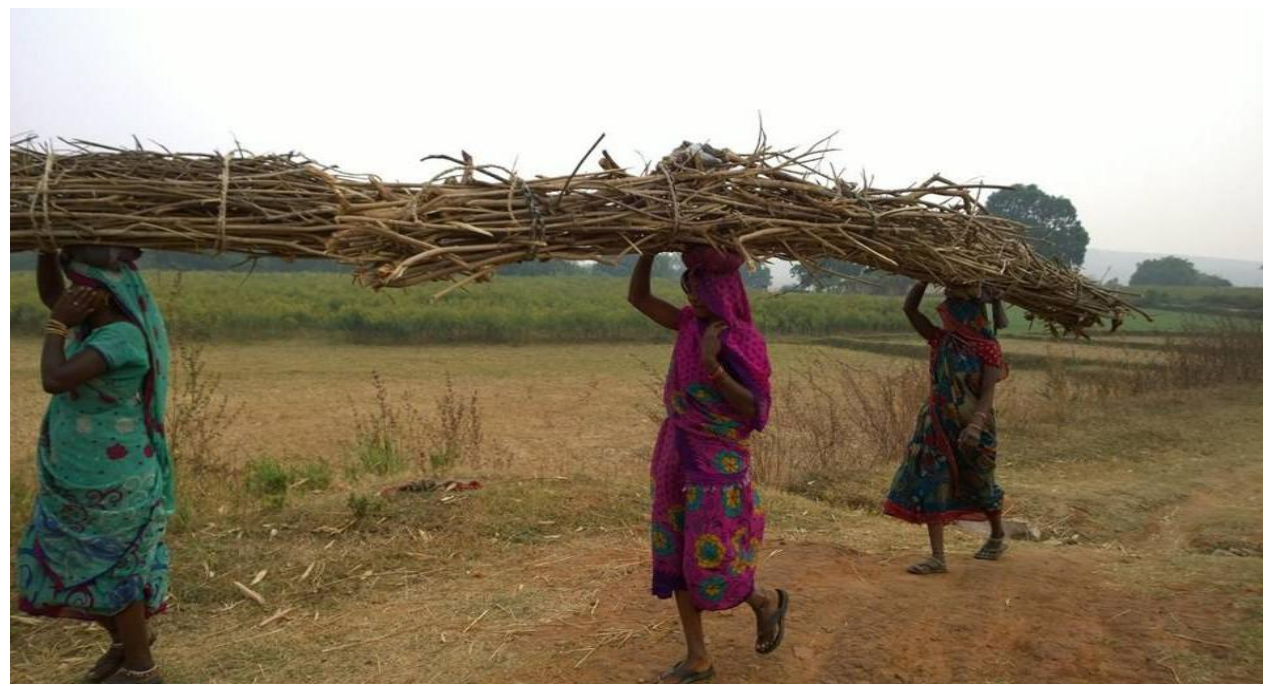

Figure 8. Kol Women Carrying Wood

The other tribal community that lives in this area is Bhil, also called Bheel. They are divided into a number of endogamous territorial groups. They are skilled hunters and it is because of their knowledge of the territory that Bhil are valued as "shikari" (hunter) and are given land by the landlords to settle down in this area. They still use their traditional ways of trapping and killing animals with bow and arrow (Figure 9), gandasa etc. The Kol and Bhil living in rural forested areas still worship their tribal gods - Bara Baba/Bara Deo, goddess shakti or Devi Mai, Karai ki Devi, Kalika Mai. Their Hinduism is intermingled with their animistic beliefs.

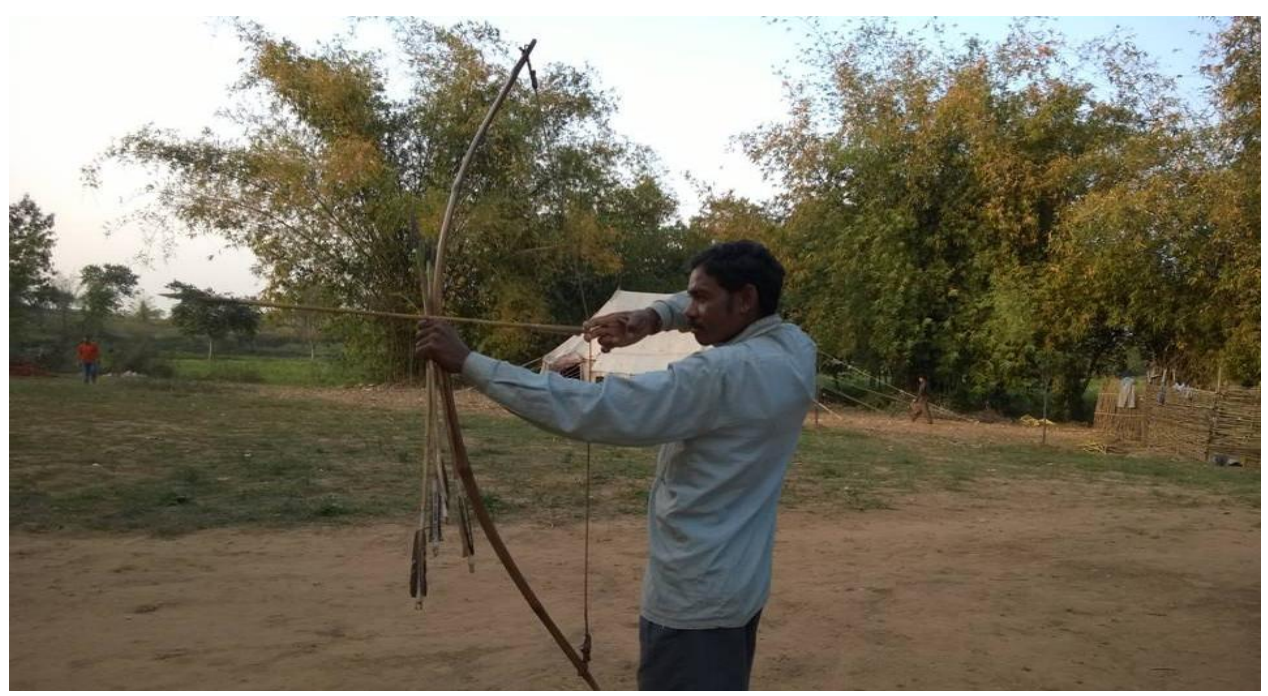

Figure 9. Bhil 


\section{Discussion}

Tribals or Adivasis have provided continuity and unparalleled vitality to culture and artistic tradition in Indian art. Stella Kramrisch has given the term "dateless art" to the vital stream of indigenous artistic tradition that is all pervasive. There is a need to explore the connection between "dateless" archaeological/anthropological art and its practices in today's world of tribal India. Even though there are different regional styles and traits visible in artistic tradition, in everyday life there is also a common thread that runs through from prehistoric times to modern days. It is remarkable that for thousands of years, peoples are rooted to their culture and the change that is imperetive is discernable in their artistic tradition. As an example, there is a ritual of painting the floor every day or on special occasions in India - the purpose of decorating mud floor is to pacify malevolent spirits and to show gratitude and pay homage to the benevolent deities. The decoration on the main doorway is essential for welcoming the household deities and the inner quarters and the kitchen is painted with auspicious signs and symbols, praying for protection of the household goddess. Even today, painted corners in conventional style could be seen on a smaller scale in the houses. This ritualistic art, practiced all over India, has regional variations and are known by different names at different regions like likhnu in Himachal Pradesh, Apna in Almora and Nainital region, mandana in Rajasthan, chowkpurana in U.P., aripana in Bihar, alpona in Bengal and Assam, pakhamba in Manipur, jinnuti in Odisha, muggu in Andhra Pradesh, kolam in Kerala, rangoli in Maharashtra and sathia in Gujrat. There is also a tradition of making dhulichitra in Tibetan Tantric Art known as dul-tson-kyil-khor ("mandala of colored powders"). To create the mandala, coloured sand particles are used over a period of time in ritualistic manner for making the artistic composition strictly following the rules given in their religion and once the ritual is over, these painstakingly made designs are erased and destroyed. Like floor paintings, creating mandala is a transient art, used for healing rituals. There are also examples of ritualistic sand paintings from other parts of the world - from the Pueblo, the Navajos, the Apaches, the Tohono O'odhams, and the Zunis tribes of Native America in southern California. Artistic creation of the transient art expresses the external reality with internal realization of the impermanence of life. Prehistoric rock paintings have superimpositions on the paintings of symbols, thus making it clear that the paintings that were made earlier are not meant to be preserved, like the life itself; it is only painted on the rock surface to celebrate an occasion or to perform a ritual. The dynamics of life, a constant movement of flux, thus is expressed by the perceiver, the artist. Thus, it becomes clear that prehistoric rock paintings encapsulate many levels of understanding. 


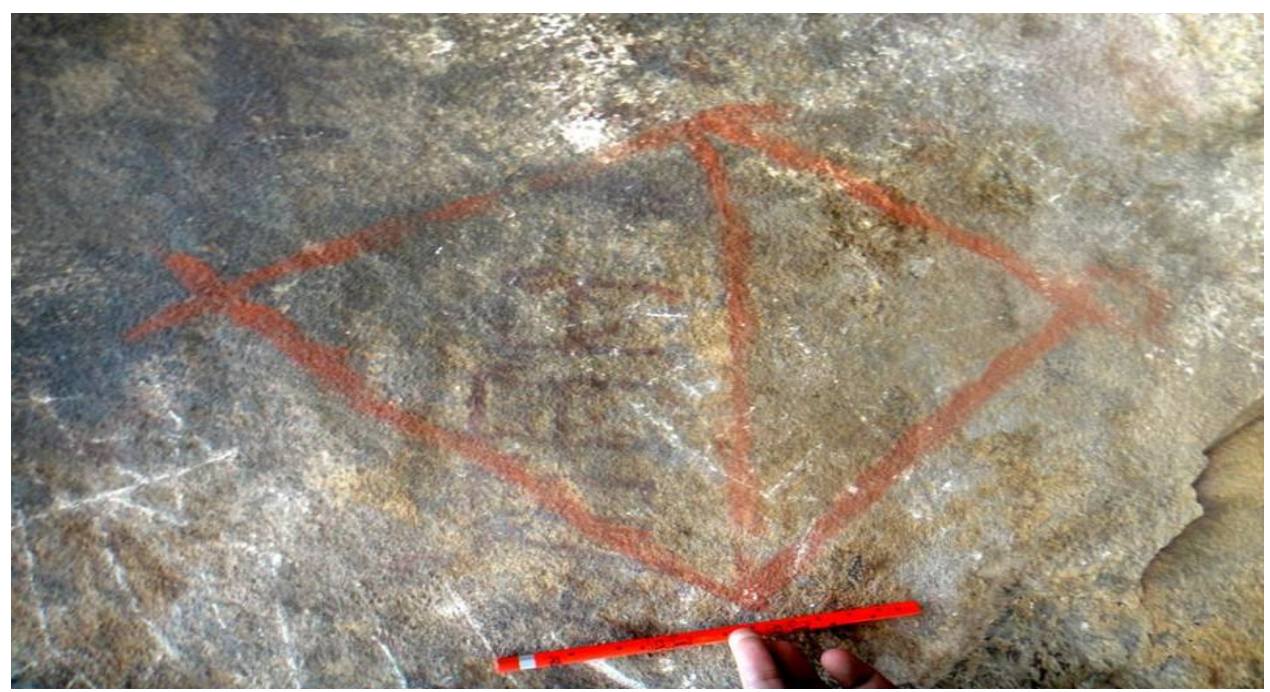

Figure 10. Symbols

There are signs and symbols drawn on the rock surfaces either on the ceiling of the shelters or high up on the wall. Among these painted symbols there are dots and circles, triangles, rectangles and squares (Figure 10). Making and using symbols show the abstraction of thought. The formal and classical elements of Indian architecture and sculpture are contained in three primary geometric forms of dot/circle, square and triangle. Bindu or dot, a metaphor of the seed is used constantly in Indian tradition. In Indian temple architecture and Buddhist stupas the structure begins at the centre, the bindu (Madhya bindu) or the bija. Bija is the Hiranyaretas (golden germ) of creation and manifestation. The "seed" also corresponds to the "egg", the golden germ (hiranya-garbha); it is the seed of the vegetative world, fetus of the animal world and womb of the human world. It is a unifying principle in Indian philosophy - Buddhist, Hindu, Jaina, or Tantra - and constitutes the basic of Indian art.

We find a continuity of painting dots and circles between the prehistoric rock paintings and in the decorative wall paintings of the present day in the villages near the rock shelters, inhabited by Kol and Bhil tribals. During spring, the festival of Holi (festival of colours) is celebrated and the homes are painted and decorated, similarly during autumn, the festival of Deepavali (festival of lights) is the time when the homes are painted and decorated afresh with different symbols and motifs. Walls and entrance to the home are also painted during auspicious occasions when Puja, rituals are performed, or at the times of marriages or other celebrations.

These paintings are mainly naturalistic - flowers and creepers, birds (Figure 11) and some geometric designs made in combination with dots, circles (representing sun), triangles, hand prints etc. In India whether it is at the highest textual tradition of the Vedas or myths and legends of tribal people like Bhil, Gond, Kol, the central theme of painting revolves around Man-Nature relationship showing the awareness of biodiversity and ecological balance. 


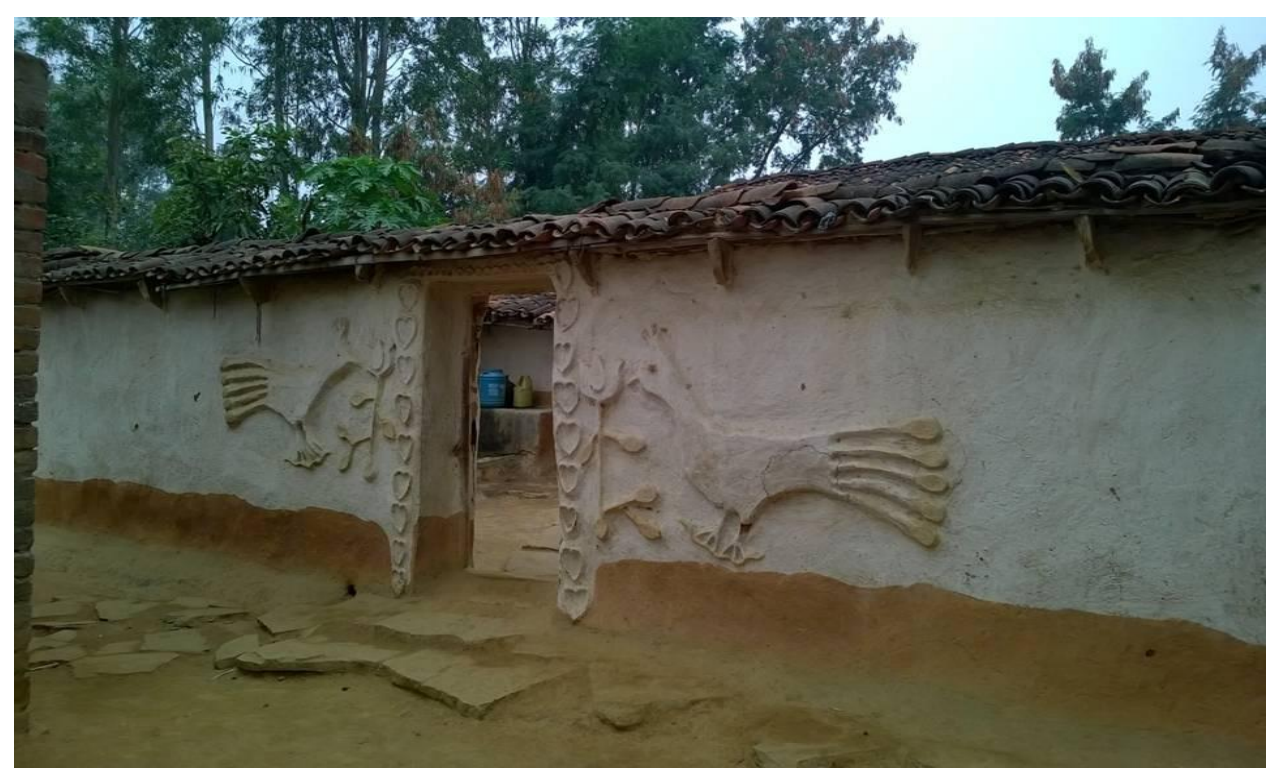

Figure 11. Modern Decoration

Another important and popular motif for painting from prehistoric period till this day is that of tree $(v r k s a)$. The tree represents connection between the earth and the heaven (axis mundi) and is universal in many ancient civilizations - Egyptian, Babylonian, Chinese and Maya, to name a few. Indian art is replete with the representation of tree, creeper and vegetation (Figure 12a \& Figure 12b) in various forms.

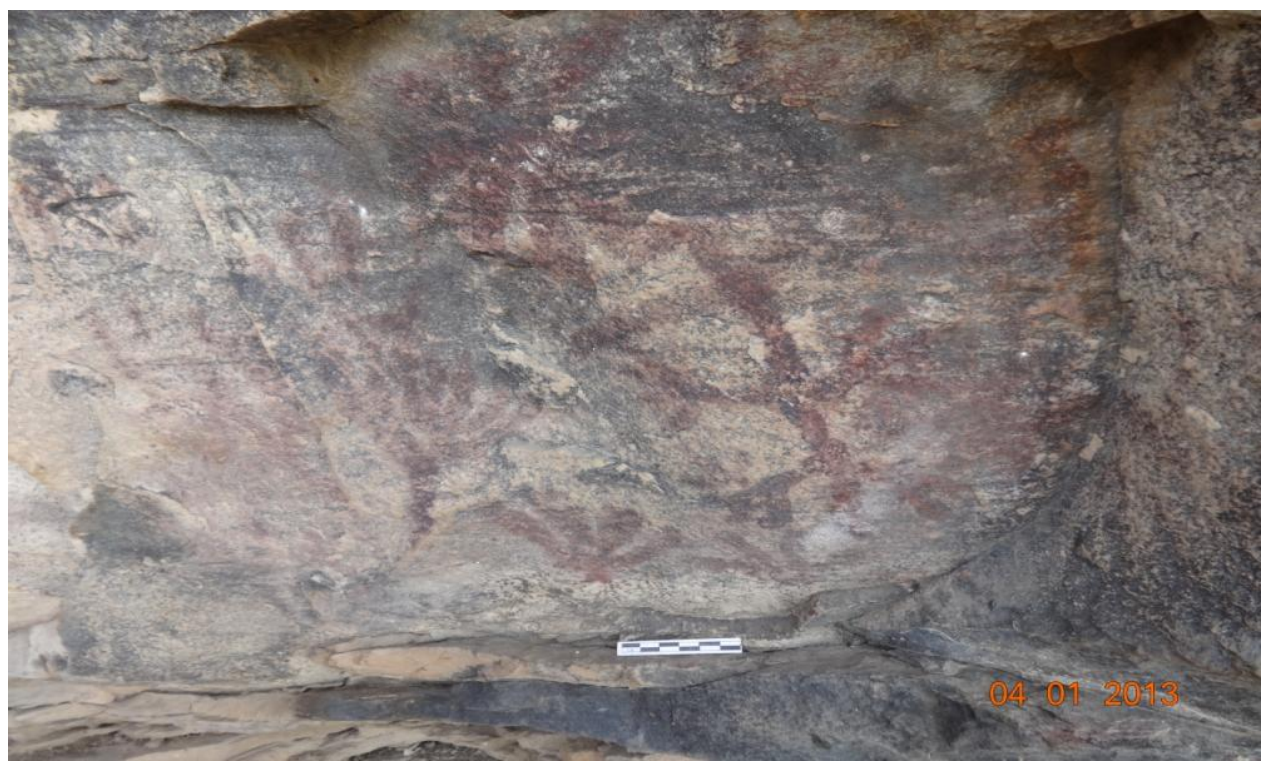

Figure 12a. Floral Decoration Rock Paintings 


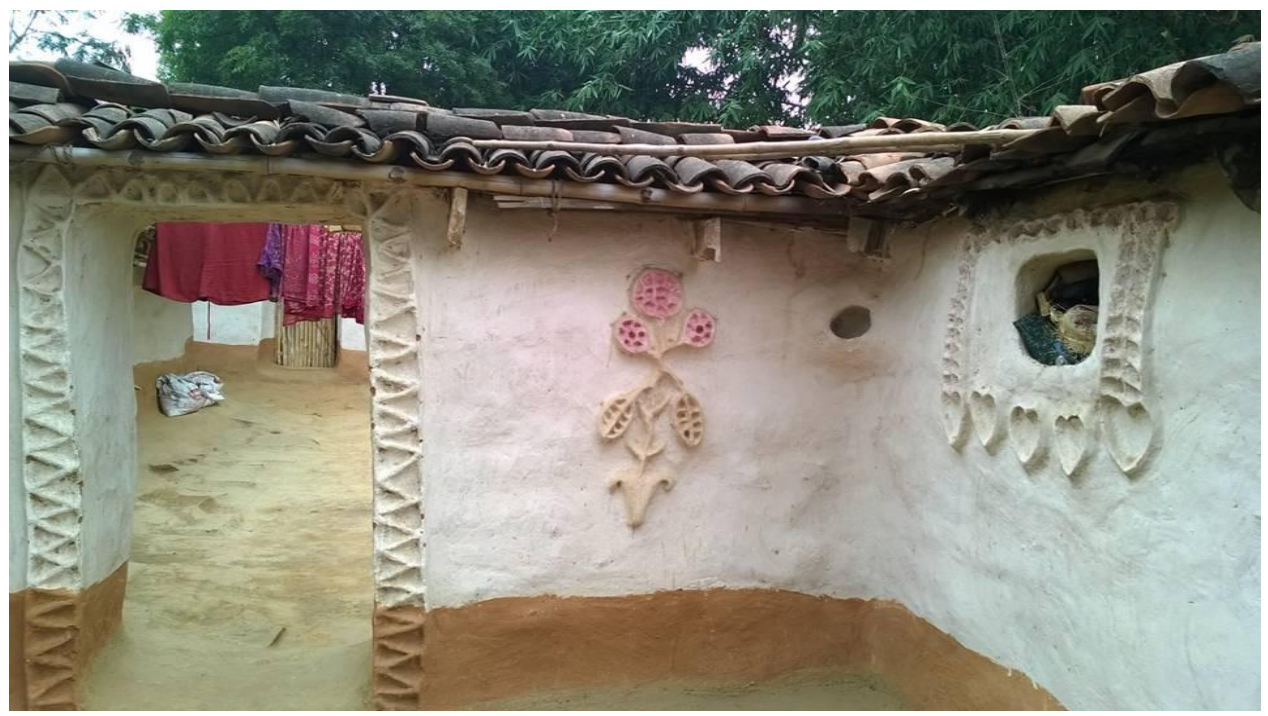

Figure 12b. Floral Decoration Modern

Another popular geometric form is the triangle. In the rock paintings that are found in association with microliths in the rock shelters of Kaimur, show painted animal and human bodies decorated with geometric designs of concentric and triangular designs (Figure 13). Triangles are also painted on the ceilings of the shelters. In Kaimur region concretionary sandstone blocks with concentric geometric formations are found (Figure 14a). The common practice among tribal people in this region is to worship stones that have "triangular laminae" as goddess, Devi, Shakti. Ethnographic references abound and confirm that these stones with triangular markings are worshipped in village shrines, left on a raised platform usually under a neem tree (Figure 14b) and are worshipped as the goddess, Devi, Shakti.

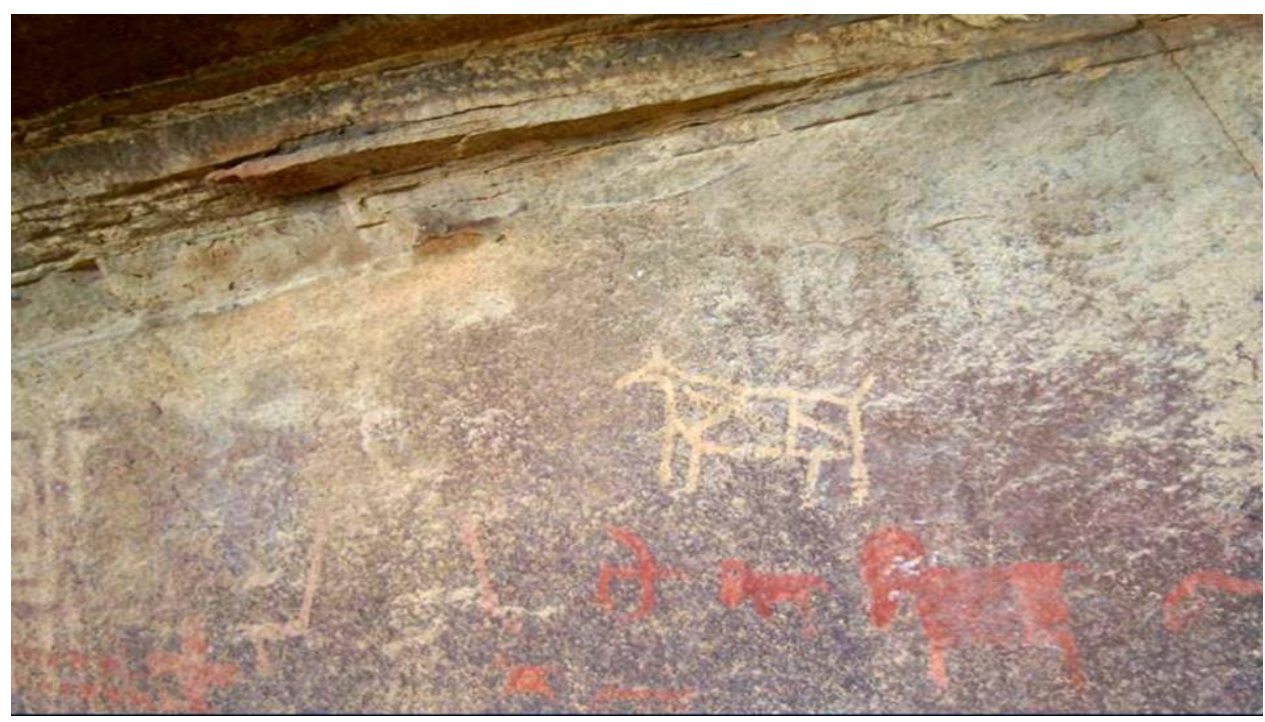

Figure 13. Triangles in Rock Painting 


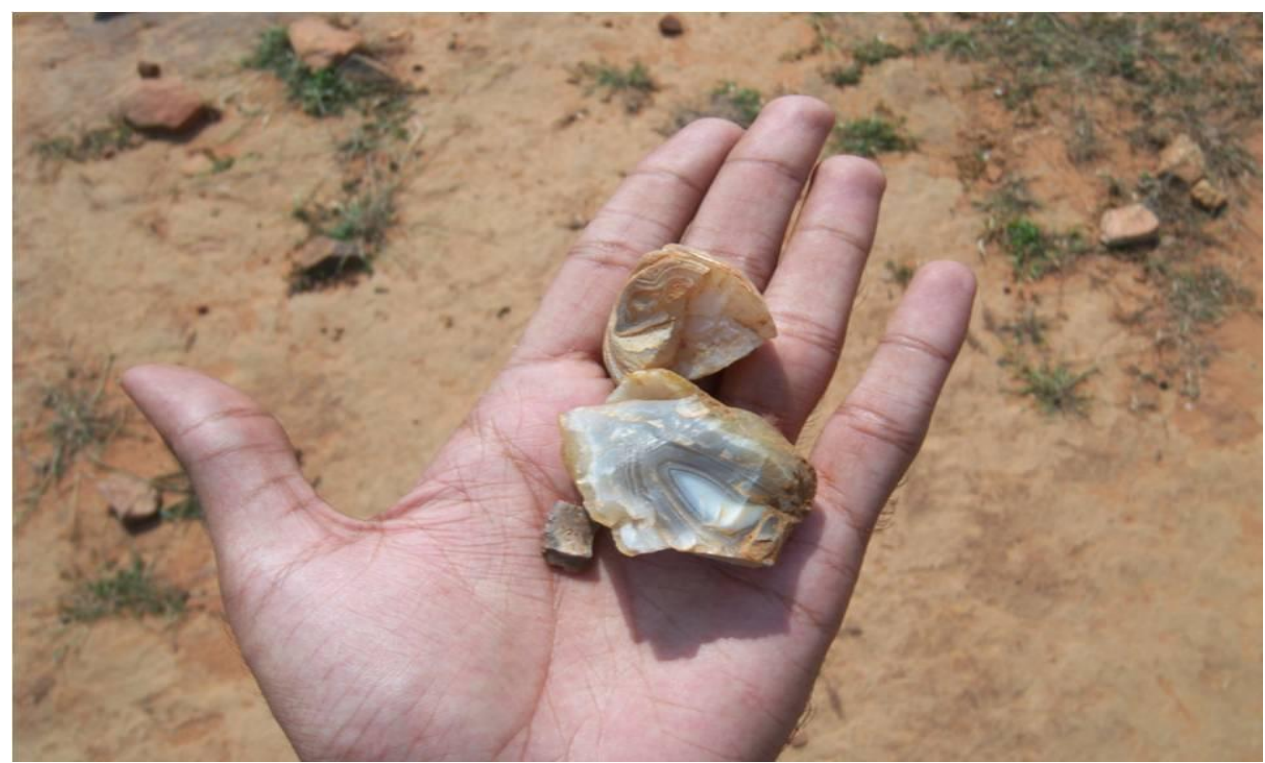

Figure 14a. Stone With Triangular Lamination

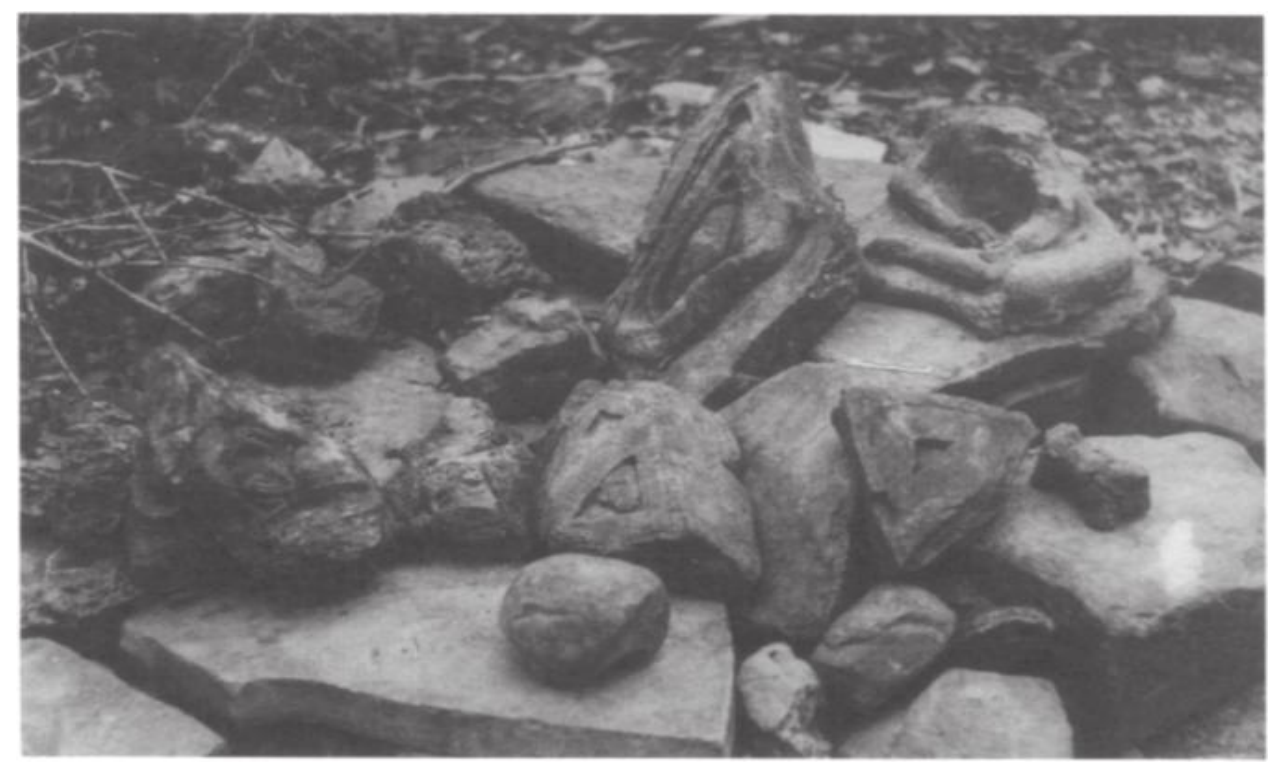

Figure 14b. Village Shrine (Courtesy Departmental Museum, Ancient History, Culture and Archaeology, University of Allahabad)

From the Upper palaeolithic site of Baghor I (Lat. $24^{\circ} 35^{\prime} 2^{\prime \prime} \mathrm{N}$. , long. $82^{\circ} 18^{\prime} 34^{\prime \prime}$ E.) near the base of Kaimur escarpment in Son river valley, Sidhi District, M.P. (India), a circular platform has been excavated with one stone (in broken condition) measuring $15 \mathrm{~cm} . X 6.5 \times 6.5 \mathrm{~cm}$ in the middle of the platform prominently showing concentric triangular lamination (Figure 15). ${ }^{26} \mathrm{~A}$ shell

26. Jonathan Mark Kenoyer et al., "An Upper Palaeolithic shrine in India?," Antiquity 57 (1983). 
sample has been dated from this site to $8330 \pm 220$ BP (PRL - 715). ${ }^{27}$ The excavators found a strong circumstantial evidence that it represents a shrine of the goddess - Shakti, worshipped by the palaeolithic hunter-gatherers living in Baghor-I locality at that time.

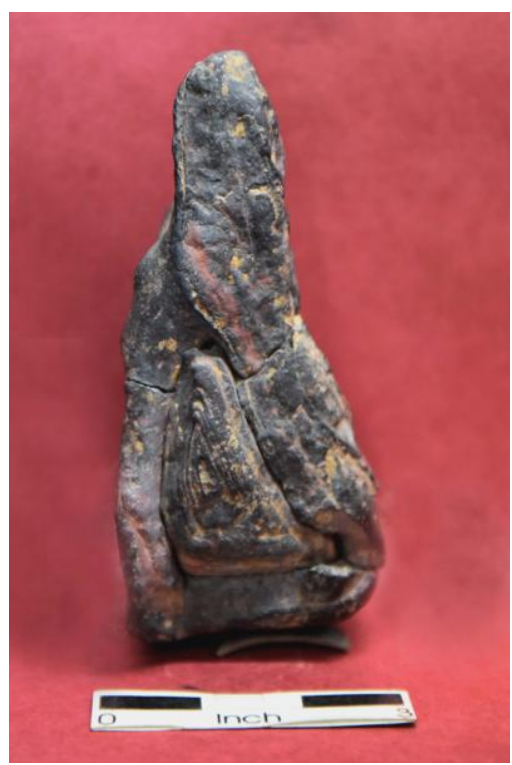

Obverse

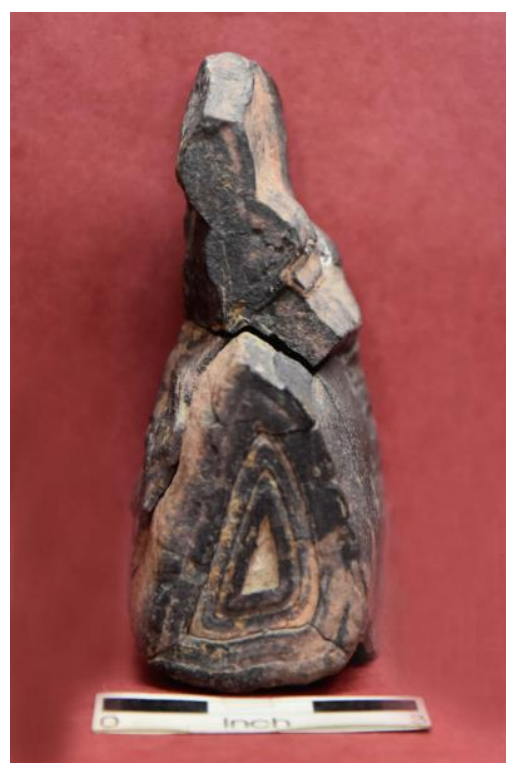

Reverse

Figure 15. Archaeological find from Baghor I (Courtesy Departmental Museum, Ancient History, Culture and Archaeology, University of Allahabad)

\section{Conclusion}

Art is related to evolutionary adaptations, drawing and painting on the rock surface show a technical skill in representing not only three dimensional things in two dimensions but also expressing emotions through line, form and colour. It is considered a major cognitive step in human evolution. The material world is multi-dimensional and viewed in different ways by different people at different times. In the Kaimur region paintings from prehistoric to early historic times are found in shallow rock shelters without occupational deposits. Acheulean handaxes, cleavers and microliths are found on the surface near the shelters. Motifs that are mostly depicted in these paintings are of animals - goat, cattle, deer, horse, elephant, wild boar and birds; also of flora and humans. There are stylistic variation in the painted human figures - depicted as stick figures, two dimensional figures and natural looking three dimensional figures (Figure 16) painted in large

27. Ibid. 
panels showing scenes of hunting, dancing, warfare and processions. The animal figures are drawn naturalistically, stylistically and effortlessly.

Paintings in the rock shelters in Sonbhadra (U.P.) could be dated to 8,000 $\mathrm{BP}$ (the Holocene period) or earlier by the archaeological finds from the area and relative stylistic dating of the paintings in the region of Bhimbetka (Madhya Pradesh), where excavations have unearthed habitational deposit of Upper Palaeolithic and Mesolithic periods inside the painted rock shelters. The modern Palaeoclimatic studies from the lake sediments in Rajasthan suggest that the Holocene period was a period of warmer conditions resulting in a stronger summer monsoon circulation that brought heavier rainfall to the Indian subcontinent. People who were living in caves and shelters were relying on an abundant source of food from the fauna and flora in the area that was heavily forested. Living at a height in rock shelters also gave them advantage to score the area for migrating herds of animals for hunting. There are many hunting scenes depicted in the rock paintings as well as the dancing scenes - both in stick figures style of painting and as swaying rectangular figures. There is also a beautiful naturalistic painting of a man riding a horse.

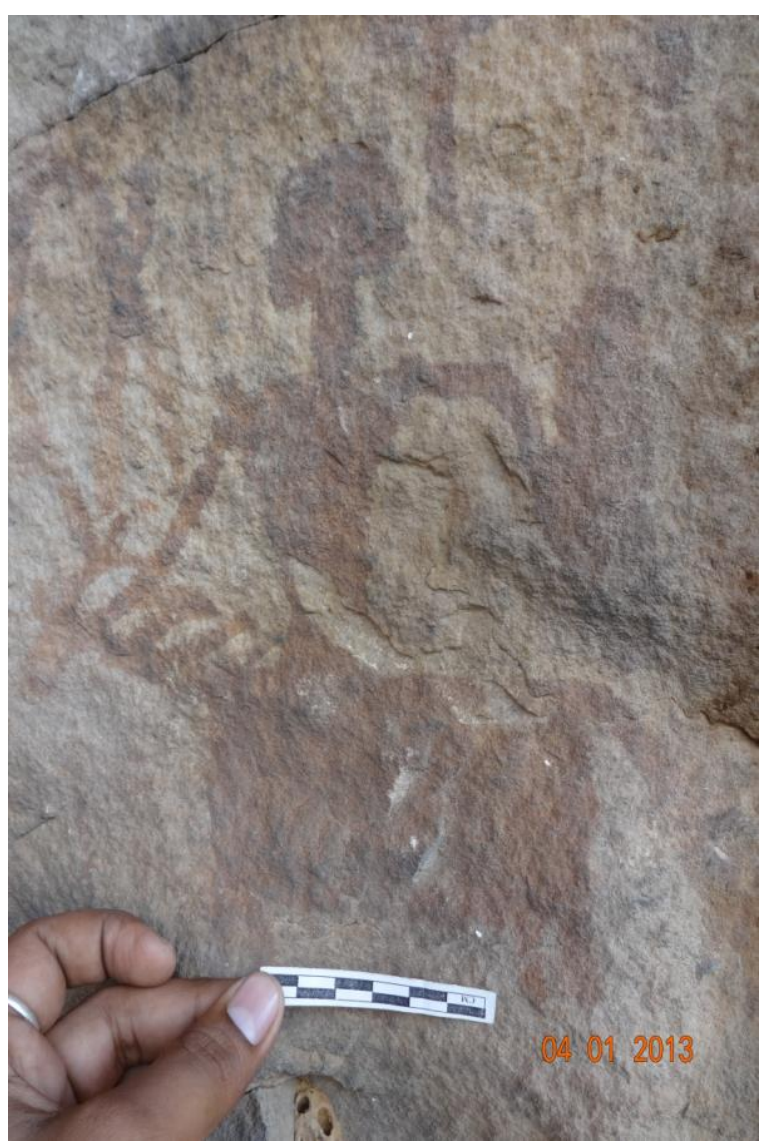

Figure 16. Man Riding Horse (Rock Painting) 
How could we decipher the meaning of these prehistoric paintings? In this particular area we have living populations of Kol and Bhil tribes who are good hunters. They still live on forest produce - gathering wood, wild fruits and honey and selling them in the village market (haat). Though they have started worshiping Hindu deities now, they still believe and worship their ancestral Gods and Goddesses like "Bara Baba", "Bara Deo", "Karika Mai", "Karei $k i$ Devi" as well as particular trees and water bodies. They also believe in witch craft. The motifs that they paint in decorating their houses are animals, birds, fruit bearing plants and creepers and some symbols like dots, circles, triangles, squares, rectangles and motifs like sun, moon and palm prints. These motifs are similar to the ones that are painted in rock shelters. This definitely shows the traces of the past and its continuity in the cultural tradition (Paramparā) - a link between the past and the present. Thus, we could trace our cultural roots from prehistoric times.

\section{Acknowledgments}

I am deeply indebted to Dr. Jitendra Kumar Singh, who has helped me in my data collection for this research. I am most grateful to Pardesi for guiding me to the painted rock shelters, in addition I would like to thank all those many others in the villages of Sonbhadra (U.P.) from whose wisdom and information I have been benefited. The field work opportunities in this research has been funded by Research \& Development Grant for the Faculty members by the University of Delhi. For this I am most grateful.

\section{References}

Alpert, Barbara Olins. The Creative Ice Age Brain: Cave Art in the Light of Neuroscience. New York: Foundation 20 21, 2008.

Blumenschine, Robert. J., and Umesh Chandra Chattopadhyaya. "A preliminary report on the terminal Pleistocene fauna of the Middle Son valley." In Palaeoenvironments and Prehistory in the Middle Son Valley, edited by Govardhan Rai Sharma and Desmond Clark. Allahabad: Abinash Prakashan, 1983.

Bradley, Richard. "Symbols and signposts - understanding the prehistoric petroglyphs of the British Isles." In The Ancient Mind: Elements of a Cognitive Archaeology, edited by Colin Renfrew, and Ezra Zubrow. Cambridge: Cambridge University Press, 1994. 
Carllyle, Archibald Campbell. "Notes on lately discovered Sepulchral Mounds, Cairns, Caves, Cave Paintings and Stone Implements." Proceedings of the Asiatic Society of Bengal (1883): 49-55.

Clottes, Jean, David Lewis-Williams. "The mind in the cave- the cave in the mind: altered consciousness in the Upper Palaeolithic." Anthropology of Consciousness 9 (1998): 13-21.

Conkey, Margaret. "Boundedness in art and society." In Symbolic and Structural Archaeology, edited by Ian Hodder, 115-128. Cambridge: Cambridge University Press, 1982.

Conkey, Margaret. "Structural and semiotic approaches." In The Handbook of Rock Art Research, edited by David Whitley, 273-310. California: Altamira Press, 2000.

Conkey, Margaret. "Hunting for images, gathering up meanings." In HunterGatherers. An interdisciplinary perspective, edited by CatherinePanter-Brick, Robert H. Layton, Peter Rowley-Conwy, 267-291. Cambridge: Cambridge University Press, 2001.

Hodder, Ian. Theory and Practice in Archaeology. London and New York: Routldge, 1992.

Jochim, Michael A. "Palaeolithic art in ecological perspective." In Huntergatherer ecology in prehistory: A European perspective, edited by Geoff $\mathrm{N}$. Bailey. Cambridge: Cambridge University Press, 1983.

Kenoyer, Jonathan Mark, John Desmond Clark, Jagannath Pal, and Govardhan Rai Sharma."An Upper Palaeolithic shrine in India?." Antiquity 57 (1983): 88-94.

Mellers, Paul. "Cognition and climate: why is Upper Palaeolithic cave art almost confined to the Franco-Cantabrian region?." In Becoming Human: Innovation in Prehistoric Material and Spiritual Culture, edited by Colin Renfrew and Iain Morley. Cambridge: Cambridge University Press, 2009.

Mithen, Steven. "Ecological Interpretations of palaeolithic art." In Contemporary Archaeology in Theory: A Reader, edited by Robert Preucel and Ian Hodder, 79-96. Oxford: Blackwell, 1996.

Ray, Niharranjan. An Approach to Indian Art. Chandigarh: Punjab University, 1974.

Renfrew, Colin. The Sapient Mind: Archaeology Meets Neuroscience. USA: Oxford University Press, 2009.

Ricoeur, Paul. Hermeneutics and Human Sciences, edited and translated by John B. Thompson. Cambridge: Cambridge University Press, 1981.

Sharma, Govardhan Rai, and Clark, Desmond. "Palaeo-environments and prehistory in the Middle Son Valley, northern Madhya Pradesh." Man and Environment 6 (1982): 56-62.

Sharma, Govardhan Rai, and Clark, Desmond. Palaeoenvironments and Prehistory in the Middle Son Valley. Allahabad: Abinash Prakashan, 1983.

Smith, Vincent A. "Pigmy flints." Indian Antiquary 35 (1906): 147-195. 
Williams, Martin A.J., and Keith. Royce. "Alluvial history of the middle Son valley, north-central India." In Palaeoenvironments and Prehistory in the Middle Son Valley, edited by Govardhan Rai Sharma and Desmond Clark, 9-21. Abinash Prakashan: Allahabad, 1983.

Williams, Martin A.J., Stanley H Ambrose, Sander van der Kaars, Carsten Ruehlemann, Umesh Chandra Chattopadhyaya, Jagannath Pal, and Parth Randhir Chauhan. "Environmental impact of the 73 ka Toba supereruption in South Asia." Palaeogeography, Palaeoeclimatology, Palaeoecology 284, no. 3-4 (2009): 295-314. 